\title{
COMMUTATORS OF FRACTIONAL INTEGRALS ON MARTINGALE MORREY SPACES
}

\author{
EIICHI NAKAI AND GAKU SADASUE
}

\begin{abstract}
On martingale Morrey spaces we give necessary and sufficient conditions for the boundedness and compactness of the commutator generated by the fractional integral and a function in the martingale Campanato space. We also give the conditions for the boundedness and compactness from martingale Morrey spaces to martingale Triebel-Lizorkin-Morrey spaces.
\end{abstract}

Mathematics subject classification (2010): Primary 60G46, Secondary 42B30, 46E30, 42B35. Keywords and phrases: Martingale, Morrey space, fractional integral, commutator.

\section{REFERENCES}

[1] R. ARAI AND E. NAKAI, Commutators of Calderón-Zygmund and generalized fractional integral operators on generalized Morrey spaces, Rev. Mat. Complut. 31 (2018), Vol. 2, 287-331, https://doi.org/10.1007/s13163-017-0251-4.

[2] S. Chanillo, A note on commutators, Indiana Univ. Math. J. 31 (1982), no. 1, 7-16.

[3] J.-A. Chao And H. Ombe, Commutators on Dyadic Martingales, Proc. Japan Acad. 61, Ser. A (1985), 35-38.

[4] J.-A. Chao And L. Peng, Schatten classes and commutators on simple martingales, Colloq. Math. 71 (1996), no. 1, 7-21.

[5] Y. CHEN, Y. Ding AND X. WANG, Compactness of commutators of Riesz potential on Morrey spaces, Potential Anal. 30 (2009), no. 4, 301-313.

[6] G. Di Fazio And M. A. Ragusa, Commutators and Morrey spaces, Boll. Un. Mat. Ital. A (7) 5 (1991), no. 3, 323-332.

[7] Z. HAO AND Y. JiAO, Fractional integral on martingale Hardy spaces with variable exponents, Fract. Calc. Appl. Anal. 18 (2015), no. 5, 1128-1145.

[8] S. JANSON, BMO and commutators of martingale transforms, Ann. Inst. Fourier (Grenoble) 31 (1981), no. 1, viii, 265-270.

[9] Y. KOMORI-FURUYA, Local good- $\lambda$ estimate for the sharp maximal function and weighted Morrey space, J. Funct. Spaces 2015, Art. ID 651825, 4 pp.

[10] T. Miyamoto, E. Nakai And G. Sadasue, Martingale Orlicz-Hardy spaces, Math. Nachr. 285 (2012), no. 5-6, 670-686.

[11] E. Nakai And G. Sadasue, Martingale Morrey-Campanato spaces and fractional integrals, J. Funct. Spaces Appl. 2012 (2012), Article ID 673929, 29 pages, doi:10.1155/2012/673929.

[12] E. NAKAI AND G. SADASUE, Characterizations of boundedness for generalized fractional integrals on martingale Morrey spaces, Math. Inequalities Appl. 20 (2017), no. 4, 929-947, doi : 10.7153/mia-2017-20-58

[13] E. Nakai, G. Sadasue And Y. Sawano, Martingale Morrey-Hardy and Campanato-Hardy Spaces, J. Funct. Spaces Appl. 2013 (2013), Article ID 690258, 14 pages, doi:10.1155/2013/ 690258.

[14] M. PaluszyńSki, Characterization of the Besov spaces via the commutator operator of Coifman, Rochberg and Weiss, Indiana Univ. Math. J. 44 (1995), no. 1, 1-17.

[15] M. A. Ragusa And A. SCAPEllato, Mixed Morrey spaces and their applications to partial differential equations, Nonlinear Anal. 151 (2017), 51-65. 
[16] G. Sadasue, Fractional integrals on martingale Hardy spaces for $0<p \leqslant 1$, Mem. Osaka Kyoiku Univ. Ser. III Nat. Sci. Appl. Sci. 60 (2011), no. 1 1-7.

[17] G. Sadasue, Martingale Besov spaces and martingale Triebel-Lizorkin spaces, to appear in Sci. Math. Jpn.

[18] C. WATARI, Multipliers for Walsh Fourier series, Tohoku Math. J. 16 (1964), 239-251.

[19] F. WEISZ, Martingale Hardy spaces and their applications in Fourier analysis, Lecture Notes in Mathematics, 1568, Springer-Verlag, Berlin, 1994. 